Formar cidadãos capazes de se sensibilizar e se solidarizar com as vítimas das desigualdades e injustiças que marcam nossa sociedade é o objetivo a que os diferentes projetos de ações sociais formulados por escolas da rede privada têm se proposto a atingir. $\mathrm{O}$ que se observa, porém, é que isso não tem sido alcançado. Não pela incompetência dos educadores em trabalhar com a questão, mas pela impossibilidade estrutural do empreendimento: não se educa para a solidariedade. Educação; solidariedade

EDUCATE FOR SYMPATHY: IS IT POSSIBLE TO DONATE WILLINGNESS?

Educating citizens able to be sensitive and sympathetic for victims of the lack of equality and fairness of our society is the aim that different social projects of private schools has proposed to reach. However, it is noticed that this objective has not been reached. This is not due to the incompetence of the educators to work with this question, but to the structural impossibility of the project: we do not educate for sympathy. Education; sympathy

\section{EDUCAR PARA A SOLIDARIEDADE: DOA-SE O DESEJO?'}

Nanci Miyo Mitsumori

Valéria Amâncio

Po pessoas, 21 milhões de indigentes, analfabetismo funcional de 49 milhões de pessoas com idade superior a 15 anos. São alguns dos números que nos dão a amostra de um Brasil marcado por imensas desigualdades sociais e econômicas, que acabam por lançar uma grande parcela da população à margem de seus processos de desenvolvimento. Uma situação inquietante que tem levado os diferentes segmentos da sociedade a pensar essas questões e a se mobilizar para a busca de alternativas.

A área da educação não fica, certamente, imune e muito menos alheia a tudo isso. Nesse sentido, o que temos podido perceber é um crescimento no número de projetos pedagógicos direcionados para as camadas mais desfavorecidas da população. São trabalhos de naturezas diversas, que vão desde a arrecadação de bens para posterior doação a entida-

Membro do Grupo Ponte da Pré-Escola Terapêutica Lugar de Vida, doutoranda em Educação pela FEUSP, Professora do curso de Pedagogia da Faculdade Taboão da Serra, psicopedagoga clínica e institucional.

- - Membro do Grupo Ponte da Pré-Escola Terapêutica Lugar de Vida, psicóloga, orientadora educacional. 
des assistenciais, até a mobilização da comunidade escolar para uma atuação que se dirija sem intermediários às pessoas carentes.

Em nosso país, a proposição de tais ações está quase exclusivamente restrita ao ensino particular, ficando a escola pública, muitas vezes, posicionada como um dos alvos dessas obras, ou seja, como destinatária das doações de bens e/ou serviços. Levantamos a hipótese de que isso ocorre em função da diferença entre o público atendido pelas duas redes. A idéia veiculada pelo discurso social é que existe uma discrepância qualitativa muito grande no trabalho desenvolvido pelos dois sistemas de ensino. Não raras vezes lemos e ouvimos comentários sobre a degradação do ensino público. Com isso, as camadas economicamente mais favorecidas da população optam pelas escolas particulares, ficando nas públicas, geralmente, aqueles cujas famílias não têm nenhuma condição de arcar com as despesas do ensino privado.

Para além dos objetivos específicos a que visa cada um desses projetos, existe um de caráter mais geral: sensibilizar os educandos para os graves problemas sociais que nos inquietam, levando-os a desenvolver um espírito de solidariedade e cooperação. Atendem, nesse sentido, às orientações dos Parâmetros Curriculares Nacionais (Brasil, 1998), que afirmam dever a escola contemplar um conjunto de temas de interesse social - os chamados temas ou eixos transversais - que possibilitem a aquisição de conhecimentos, atitudes e hábitos "adequados", e o conseqüente exercício de uma cidadania mais saudável, justa e solidária.

O pressuposto é que a educação tem um papel essencial "no desenvolvimento contínuo, tanto das pessoas como das sociedades (..) entre outros caminhos, e para além deles, como uma via que conduza a um desenvolvimento humano mais harmonioso, mais autêntico, de modo a fazer recuar a pobreza, a exclusão social, as incompreensões, as opressões, as guerras...", conforme podemos ler no Relatório para a Unesco produzido pela Comissão Internacional sobre a Educação para o Século XXI (Delors, 1997, p. 11).

Apesar das avaliaçōes positivas que são feitas em relação a algumas dessas propostas, um dado de nossa observação mostra que não há mudança nessa situação de exclusão social. A nossa questão é investigar por que esse tipo de trabalho não tem levado à formação de cidadãos mais solidários, sensíveis, capazes de mudar esse quadro. Seria pela incapacidade dos professores em trabalhar com essas questões? Ou haveria um equívoco estrutural na concepção desses projetos? Alinhamo-nos a esta segunda hipótese. A partir de uma leitura psicanalítica de orientação lacaniana, consideramos que a meta por eles colocada é da ordem do impossível: não se educa para a solidariedade. 
Exploremos melhor essa idéia.

Um primeiro ponto que destacamos é a concepção de homem. Essas propostas estão apoiadas em uma noção de homem indiviso, orientado somente pelo plano da consciência, que poderia, a partir do pensamento, da racionalidade, caminhar para um progressivo conhecimento e controle de si mesmo e dos objetos do mundo. Dessa forma, consideram que há possibilidade de formar seres mais solidários a partir de um ensino, uma transmissão, que não deixe de lado a ação prática, o contato com a realidade concreta.

A psicanálise, ao trazer a noção de sujeito para o centro de suas articulações, segue por uma via totalmente distinta. Para Lacan, o sujeito não está no plano da consciência do eu. No texto de 1949, sobre o Estádio do Espelho, o autor assinala que esse eu tem um caráter alienante: formado pelos outros, pelos discursos desses outros humanos que estabelecem para a criança quem ela é, com quem se parece, o que ela sente, etc., traz em si as marcas da ilusão. O que esses discursos veiculam é uma imagem idealizada que o sujeito toma como sua, mas que, em última instância, jamais alcançará. O que se passa aí é da ordem da identificação, "a transformação produzida no sujeito quando assume uma imagem" (Lacan, 1949 , p. 87).

Essa é a primeira forma organizada da constituição subjetiva, o primeiro recorte que alguém pode fazer num real que é, até então, pura dispersão. Como afirma de Lajonquière, trata-se de uma "espécie de operação de ancoragem que [...] possibilita a um sujeito construir uma realidade externa e fazer uso normativo de uma linguagem qualquer (isto é, falar como sendo UM que não se confunde com os outros)" (1992, p. 164).

O mais importante a perceber é que esse jogo de imagens que acaba por precipitar um eu está simbolicamente orientado: esses outros humanos que dão contorno a isso que é só uma imagem não o fazem senão na condição de suporte do Outro, que é, segundo a psicanálise, o lugar do código de significantes cuja circulação produz efeitos de filiação, de inserção dos sujeitos em uma cultura, em uma história. Assim, é da sua vinculação ao desejo formulado pelo Outro que a imagem especular extrai sua eficácia simbólica, a garantia de que a criança vai "consentir" em aí se lançar.

A experiência do Estádio do Espelho configura-se, portanto, na relação do sujeito com os significantes, com a linguagem. Porém, é da natureza própria da linguagem que ela não consiga dizer, recobrir o todo; ela introduz um corte entre o que se diz e o que se quer dizer.

Da mesma forma, ao atravessar o sujeito, a linguagem o lança em uma divisão fundamental em relação a si mesmo: entre um eu que poderá se atribuir uma identidade, certezas, pensamentos ou sentimentos como o de solidariedade -, e o Inconsciente, cujo controle escapa totalmente ao plano da consciência, e que não se deixa apanhar por nenhuma representação. Como afirma Pereira, "a busca, por conseguinte, do sujeito autônomo, ideal, senhor de seus atos e agente da história, à 
luz da psicanálise (...), pode se tornar um empreendimento utópico, pois a universalidade não sabe tudo. O discurso do sujeito sempre deixará um resto cuja verdade particular é meio-dita" (1998, pp. 183-4).

Alguns poderiam argumentar que, em última instância, no processo educativo só se consegue falar ao $e u$, ao aluno "imaginarizado", ficando a cargo de cada educador fazê-lo supondo ali um sujeito, e apostando na possibilidade de que esses conhecimentos "vazem" para o saber do inconsciente (Kupfer, 2000).

$O$ que precisamos considerar nesse caso, porém, é a natureza do conteúdo em questão. Não se está falando somente de saberes dados pela cultura, e dos quais o sujeito pode se servir para elaborar a sua posição, a sua forma de estar no mundo, mas de um conteúdo que concerne à própria subjetividade e à relação desse sujeito com um outro; esse com quem ele deveria supostamente aprender a conviver, a se solidarizar e a cooperar.

Seria isso possivel? E quem, afinal, é esse outro?

Em psicanálise, a concepção de outro é abordada por duas vertentes, como se pode depreender das formulações que fizemos em relação ao processo de constituição do sujeito. Temos, assim:

a) o outro como um semelhante, com quem o sujeito se identifica. Trata-se do outro que ele compreende, da mesma forma que é por ele compreendido; e

b) o Outro, que se refere ao registro Simbólico, a essa linguagem que, ao atravessar o sujeito, instaura um corte entre aquilo que será o seu mundo de imagens e símbolos e uma área que the ficará para sempre perdida, que nenhuma representação poderá recobrir.

$O$ que a análise dos projetos de ações sociais desenvolvidos pelas escolas nos mostra é que eles consideram somente a primeira face do outro. Desde o início de sua proposição, já se tem um saber sobre aquilo que seria a necessidade do público "beneficiado". Quanto a isso, não há nenhum questionamento, pois impera a certeza sobre o objeto que atenderia a essa necessidade. Para os meninos de rua, um abrigo; para as crianças pobres, brinquedos e agasalhos, por exemplo.

Entramos aqui em contato com o que Lacan revela ser a lógica própria do altruísmo como manifestação do mais puro egoísmo. O que se evidencia é que o sujeito, sim, ele quer o bem do outro, mas somente sob certas condições. Primeiro, que esse bem seja o mesmo que o sujeito quereria para ele naquela situação. E, depois, que seja ele próprio o agente da realização desse bem.

Uma lógica tão presente em nossas sociedades contemporâneas, que são, mais do que nunca, regidas segundo uma ética utilitária: é proveitoso e bom aquilo que o for para a grande maioria.

A consideração da outra face do outro, ou seja, do Outro, faria vacilar essa lógica, essa certeza sobre o bem do outro, pois nesse nível o homem entra em contato com um enigma, uma zona vazia de qualquer significante que possa dizer sobre esse bem.

Como afirma Lacan:

"Enquanto se trata do bem, não 
há problema - o nosso e o do outro são feitos do mesmo pano. São Martinho partilha seu manto, e disso se fez uma longa história, mas, enfim, é uma simples questão de domesticação, o pano é, por natureza, feito para ser espalhado, ele tanto pertence ao outro quanto a mim. Certamente tocamos aí num termo primitivo, a necessidade que deve ser satisfeita, pois o mendigo está nu. Mas talvez, para além de precisar vestir-se, mendigava ele outra coisa, que São Martinho o matasse, ou que trepasse com ele. É uma questão muito diferente a de saber o que significava num encontro a resposta, não da beneficência, mas do amor" (1959-60, p. 228).

No seminário em questão, "A ética da psicanálise", Lacan discute as relações do homem com o outro a partir do horror que o mandamento bíblico de amar ao próximo como a si mesmo causou em Freud. Horror que se deve à constatação da impossibilidade do cumprimento desse mandamento, em função da precioșidade desse amor - que não se dá a qualquer um -, e da maldade que existe no próximo.

$\mathrm{O}$ autor reverte formulações freudianas para dizer que o que na verdade se impõe como barreira a esse mandamento é o gozo.

A partir do gozo sexual como paradigma de todo gozo, podemos inferir que não existe, nunca, um "feliz encontro" entre o sujeito e o outro. Como afirma Julien, "não há resposta para a questão: 'Será que o gozo segundo o qual um goza com o outro é o mesmo gozo segundo o qual o outro goza com o um?’” (1996, p. 53).

No nível do gozo, não há qualquer possibilidade de um bementendido, pois estamos num campo em que faltam os significantes. Campo que, justamente, é instaurado no momento em que o sujeito, pela operação de separação produzida pela linguagem, acede a sua condição de sujeito desejante. Paradoxalmente, isso implicará que o objeto que satisfaria esse desejo fica para sempre perdido, pois se "institui uma distância irredutível entre o sujeito e o objeto do seu desejo, distância essa que é o próprio desejo" (Rinaldi, 1996, p. 78).

Assim, ao se aterem ao plano das necessidades, o que os projetos educativos de ações sociais não contemplam é que não existe nenhuma possibilidade de ofertar um objeto que realize o desejo. O desejo é indo(m)ável.

Chegamos então a um ponto crucial. Se não existe essa possibilidade, e se tudo o que se pode ofertar em termos de bens está relacionado ao egoísmo do sujeito, perguntamos: deve então a educação conformar-se com os limites impostos pelo Outro, e desistir de todos esses projetos?

Nossa resposta é não. Desde que esses trabalhos possam levar em conta essas dimensões, tudo aquilo que, no sujeito, é imprevi- 
sível, inadaptável, ineducável propriamente falando. E que possam criar espaços para que cada um se implique com o seu desejo e o próprio gozo, abrindo-se para o que seria, conforme Zizek, "o autêntico trabalho de amor [que] não reside em ajudar o outro como se estivéssemos atirando migalhas de nossa riqueza por meio da barreira de segurança: é, sobretudo, o trabalho de desmantelar essa barreira, de alcançar diretamente o sofrimento do outro" (2001, p. 19).

Uma alternativa, nesse sentido, seria a instauração, no cerne dessas propostas, disso que se denomina a grande conversação, permitindo que cada sujeito recoloque a própria palavra em circulação “a partir do descobrimento [...] do que é nomeável e inomeável [...] para dar lugar às verdadeiras distinções, uma a uma" (Laurent, 1999, p. 60).

\section{REFERÊNCIAS BIBLIOGRÁFICAS}

Brasil, Secretaria de Educação Fundamental (1998). Parâmetros Curriculares Nacionais - Terceiro e Quarto Ciclos. Apresentação dos temas transversais. Brasília, DF: MEC/SEF.

Delors, J. (1997). Educafão: um tesouro a descobrir. Relatório para a Unesco produzido pela Comissão Internacional sobre a Educação para o Século XXI. São Paulo, SP/Brasília, DF: Cortez/MEC.

Julien, P. (1996). O estranho gozo do próximo: ética e psicanálise. Rio de Janeiro, RJ: Jorge Zahar.

Kupfer, M. C. M. (2000). Educação para o futuro: psicanálise e educação. São Pau1o, SP: Escuta.

Lacan, J. (1949). El estadio del espejo como formador de la función del yo lje] tal como se nos revela en la experiencia psicoanalítica. In Escritos. Cidade do México: Siglo Veintiuno, 1990.

(1959-60). O seminário. Livro VI, A

ética da psicanálise. Rio de Janeiro, RJ: Jorge Zahar, 1997.

Laurent, E. (1999). Segregación y diferenciación. El Niño - Revista del Instituto del Campo Freudiano. CIEN, 6, pp. 54-64.

Lajonquière, L. de (1992). De Piaget a Freud: a (psico)pedagogial entre o conhecimento e o saber. Petrópolis, RJ: Vozes.

Pereira, M. R. (1998). O relacional e seu avesso na ação do bom professor. In Lopes, E. M. T. (org.). A psicanálise escuta a educaļão. Belo Horizonte, MG: Autêntica, pp. 151-93.

Rinaldi, D. (1996). A ética da diferença: um debate entre psicanálise e antropologia. Rio de Janeiro, RJ: Jorge Zahar.

Zizek, S. (2001). O espectro do cigarro. In Folha de S. Palulo, Caderno Mais (9/9), pp. 18-9.

\section{NOTA}

1 Trabalho apresentado no Colóquio Universitário Franco-Brasileiro realizado pela Universidade de Paris 13 entre os dias 5 e 7 de outubro de 2001, em Paris.

Recebido em novembro/2001. 